\author{
Journal of Research of the National Bureau of Standards \\ Volume 91, Number 1, January-February 1986
}

\title{
Development of a Standard Reference Material for Rainwater Analysis
}

\author{
William F. Koch, George Marinenko, and Robert C. Paule \\ National Bureau of Standards, Gaithersburg, MD 20899
}

\begin{abstract}
Accepted: October 9, 1985
This paper describes the development of Standard Reference Material, SRM 2694, "Simulated Rainwater," intended to aid in the analysis of acidic rainfall. Details of the formulation and preparation of the two levels of solutions (2694-I and 2694-II) are given. The 10 analytical techniques used to measure the 12 components in the solutions are described in brief. The data used in the statistical evaluation of the results are summarized and the recommended values for $\mathrm{pH}$, specific conductance, acidity, fluoride, chloride, nitrate, sulfate, sodium, potassium, ammonium, calcium, and magnesium are tabulated. The instability of ammonium ion in acidic solutions is discussed. Recommendations for the use of SRM 2694, particularly with regard to the measurement of $\mathrm{pH}$, are given.
\end{abstract}

Key words: acid rain; acidity; ammonium; analytical chemistry; conductivity; measurement; pH; precipitation; rainwater; Standard Reference Material; statistics; sulfate.

\section{Introduction}

Wet deposition is monitored by various laboratories and agencies as part of national and international networks to record accurately the composition of rainfall. These efforts are intended to determine the extent of the problem of "acid rain," and to establish spatial and temporal trends. Discrepancies in data often occur due to differences in instruments and techniques. These discrepancies limit the conclusions which may be drawn

\footnotetext{
About the Authors: William F. Koch and George Marinenko are chemists in NBS' Inorganic Analytical Research Division, part of the Bureau's National Measurement Laboratory in which Robert C. Paule, a physical scientist, serves. The work they describe was sponsored in part by the U.S. Environmental Protection Agency (National Acid Precipitation Assessment Program).
}

from the data. To establish a common basis for chemical measurements in rainwater, a multi-year research effort has been established in the Inorganic Analytical Research Division of NBS; Center for Analytical Chemistry. This effort has resulted in the issuance of Standard Reference Material (SRM) 2694, Simulated Rainwater.

The initial stages of the evolution of this SRM are described in detail in a previous article [1]. ${ }^{1}$ In that article, the early formulations of multicomponent solutions are given, and the problems with their stability are discussed. The stability problems inherent in these early formulations stem from both the complexity of the solutions and the use of glass ampoules as storage containers. The progression to polyethylene bottles and to simplified solutions, from which the transition and heavy metals were eliminated, resulted in solutions of greater stability and overall applicability to the measurements of $\mathrm{pH}$, acidity, conductance, nitrate, and sulfate. These components are most critical to acid rain studies.

\footnotetext{
${ }^{1}$ Figures in brackets indicate literature references.
} 
Associated difficulties with the measurement of $\mathrm{pH}$ and acidity are treated in other articles [2-4].

The pressing need of the scientific community for a common reference material for rainwater and the desire by us to field test such a material led to the production and distribution of a Research Material, RM 8409, Simulated Rainwater. RMs are distinguished from SRMs according to the definitions of NBS' Office of Standard Reference Materials [5].

In brief, RMs are high quality materials whose composition has been established by a single technique for each component. The composition of SRMs is certified after much more extensive testing involving at least two independent techniques for each component or analysis by a definitive method. Often an RM uncovers unforeseen problems, as was the situation in this case. This problem involved the long-term stability of the ammonium ion. The extent of the instability and its ramifications will be addressed below. The primary focus of this paper will be the preparation, analysis, and certification of SRM 2694.

\section{The Preparation of SRM 2694}

The decision to prepare simulated rainwater, rather than collecting natural rainfall, was based on the need to minimize contamination and unwanted components that would compromise the overall stability of the solutions. We also wanted to prepare two solutions of different concentrations of the various components, and we wanted to control the levels closely. Thus, simulated rainwater prepared by the dissolution of salts and acids in water was the best recourse.

The production of this simulated rainwater involved careful coordination of several operations, including bottle cleaning, formulations, dilution, mixing, and bottling. Approximately 2000 bottles of each level were prepared.

\subsection{Bottle Cleaning}

Based on earlier research [1], low density polyethylene (LDPE) bottles (60-mL capacity) were chosen for this project. Over 4000 bottles were cleaned using a rigorous procedure to minimize contamination. In brief, this cleaning procedure consisted of rinsing and soaking the bottles and caps for extended periods with filtered, distilled/deionized water. The bottles were then dried at $40^{\circ} \mathrm{C}$ in a clean oven, and recapped until the filling operation was started. At all times, the bottles were kept away from areas with acid fumes.

\subsection{Formulation and Target Values}

Two levels of simulated rainwater containing the cations and anions commonly found in acid rain were for- mulated in such a way so as to span a useful analytical range of concentrations of all components. The target values for the two levels are shown in table 1. It should be noted that the measurement of $\mathrm{pH}$ was the primary driving force behind the development of this SRM. Hence, the stability of the solutions with respect to $\mathrm{pH}$ was an overriding constraint.

It has been found that unbuffered solutions at about pH 4.5 or above are extremely susceptible to fluctuations in $\mathrm{pH}$ and acidity due to absorption and desorption of atmospheric carbon dioxide. These processes occur even through the walls of the polyethylene bottles. For this reason, although it would have been desirable to issue a solution of pH 5.0, SRM 2694-I was targeted at $\mathrm{pH} 4.3$ as a precaution.

Table 1. Target values of SRM 2694, simulated rainwater.

\begin{tabular}{lcc}
\hline \hline & $2694-\mathrm{I}$ & $2694-\mathrm{II}$ \\
\hline $\mathrm{pH}$ & 4.3 & 3.6 \\
Specific Conductance, $\mu \mathrm{S} / \mathrm{cm}$ & 25 & 130 \\
Acidity, meq/L & 0.05 & 0.28 \\
Fluoride, mg/L & 0.05 & 0.1 \\
Chloride, mg/L & 0.25 & 1.0 \\
Nitrate, $\mathrm{mg} / \mathrm{L}$ & 0.5 & 7 \\
Sulfate, mg/L & 2.7 & 11 \\
Sodium, mg/L & 0.2 & 0.4 \\
Potassium, mg/L & 0.05 & 0.1 \\
Ammonium, mg/L & 0.1 & 1.0 \\
Calcium, mg/L & 0.01 & 0.05 \\
Magnesium, mg/L & 0.025 & 0.05 \\
\hline
\end{tabular}

\subsection{Mixing of Simulated Rainwater}

Seven ACS-reagent grade salts and three high-purity acids [6] were used in the preparation of the two levels of simulated rainwater. For convenience in the mixing process, stock solutions of the salts and acids were prepared. Table 2 lists the chemicals and the concentrations of the stock solutions. Table 3 lists the weights of each of the stock solutions used in the final dilutions of the solutions.

Table 2. Stock solutions used in the preparation of SRM 2694.

\begin{tabular}{cll}
\hline \hline Stock Solution & Chemical & \multicolumn{1}{c}{ Concentration } \\
\hline 1 & $\mathrm{NaNO}_{3}$ & $1 \mathrm{mg} \mathrm{salt} / \mathrm{g}$ solution \\
2 & $\mathrm{KNO}_{3}$ & $1 \mathrm{mg} \mathrm{salt} / \mathrm{g}$ solution \\
3 & $\mathrm{CaCl}_{2} \cdot 2 \mathrm{H}_{2} \mathrm{O}$ & $1 \mathrm{mg} \mathrm{salt} / \mathrm{g}$ solution \\
4 & $\mathrm{MgSO}_{4} \cdot 7 \mathrm{H}_{2} \mathrm{O}$ & $1 \mathrm{mg} \mathrm{salt} / \mathrm{g}$ solution \\
5 & $\mathrm{NH}_{4} \mathrm{Cl}$ & $1 \mathrm{mg} \mathrm{salt} / \mathrm{g}$ solution \\
6 & $\left(\mathrm{NH}_{4}\right)_{2} \mathrm{SO}_{4}$ & $1 \mathrm{mg} \mathrm{salt} / \mathrm{g}$ solution \\
7 & $\mathrm{H}_{2} \mathrm{SO}_{4}$ & $0.100 \mathrm{~N}(0.050 \mathrm{~mol} / \mathrm{L})$ \\
8 & $\mathrm{HNO}_{3}$ & $0.100 \mathrm{~N}(0.100 \mathrm{~mol} / \mathrm{L})$ \\
9 & $\mathrm{HCl}$ & $0.050 \mathrm{~N}(0.050 \mathrm{~mol} / \mathrm{L})$ \\
10 & $\mathrm{NaF}$ & $1 \mathrm{mg} \mathrm{salt} / \mathrm{g}$ solution \\
\hline
\end{tabular}


Table 3. The weights of the stock solutions used in the preparation of SRM 2694

\begin{tabular}{ccc}
\hline \hline Stock Solution & $\begin{array}{c}2694-\mathrm{I} \\
\text { (final volume, 170 L) }\end{array}$ & $\begin{array}{c}2694-\mathrm{II} \\
\text { (final volume, 150 L) }\end{array}$ \\
\hline 1 & 83.43 grams & 147.27 grams \\
2 & 22.06 grams & 38.74 grams \\
3 & 9.61 grams & 27.66 grams \\
4 & 34.88 grams & 61.60 grams \\
5 & 50.97 grams & 0 grams \\
6 & $0 \quad$ grams & 550.05 grams \\
7 & 85.00 grams & 225.04 grams \\
8 & 1.78 grams & 149.98 grams \\
9 & $0 \quad$ grams & 75.00 grams \\
10 & 19.89 grams & 35.24 grams \\
\hline
\end{tabular}

A 200-liter polyethylene, cylindrical tank, which had been cleaned according to the same procedure used for the bottles, was used in the final dilution of the appropriate amounts of each of the stock solutions. Graduations at 10-liter increments were made on the outside of the tank as it was being filled during the cleaning process. These marks served only as an indication of the volume, and were not intended to calibrate the volume accurately. A stirring motor with a teflon paddle was used to thoroughly mix the solutions. Figure 1 shows the apparatus in operation.

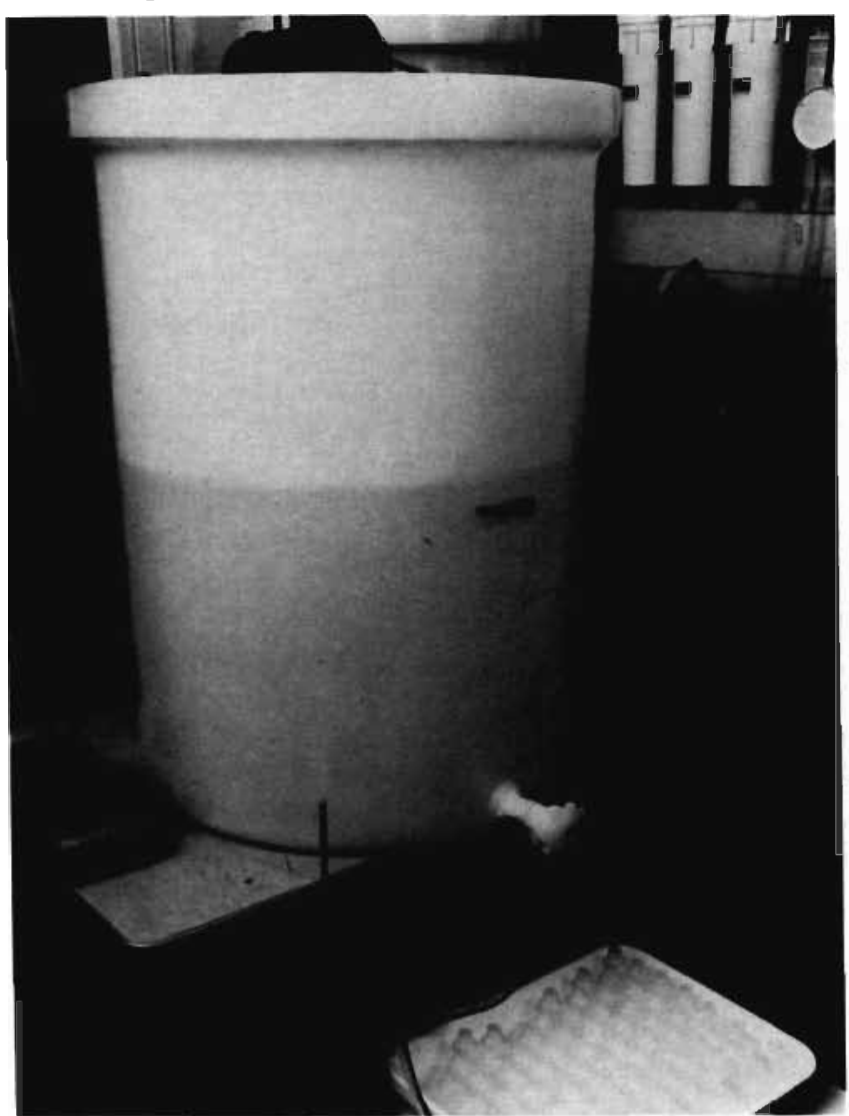

Figure 1-Apparatus used in the preparation and dispensing of SRM 2694.
Approximately 170 liters of 2694-I and approximately 150 liters of 2694-II were prepared in February 1985, according to the following procedure. The calculated amounts of each of stock solutions \#1 through \#9, (see table 3), were added to 100 liters of filtered, distilled/ deionized water in the tank. The resulting solution was mixed thoroughly. Then the calculated amount of solution \#10 (sodium fluoride) was slowly added. It was necessary to delay the input of sodium fluoride to prevent the possible precipitation of calcium fluoride, which is extremely difficult to redissolve. Filtered, distilled/deionized water was then added to bring the total volume to the pre-established mark. The solution was thoroughly homogenized by intermittent vigorous stirring over a 24 -hour period. Note that although care was taken to add exact amounts of each component and to dilute with the correct amount of water, there was no convenient way to accurately assess the final volume. Hence, the weights and volumes could not be used as an analytical measure of the concentrations of the various components. This was left to the analytical chemists and their myriad of techniques.

\subsection{Bottling}

Before the bottling commenced, a sample of each level was analyzed by ion chromatography and potentiometry to verify that the target values had been met. The bottling of each level was completed in a single day. The bottles were filled manually, capped immediately, and placed sequentially in numbered cartons. Concurrent with the bottling operation, a homogeneity test was run. One out of every 120 bottles was pulled from the line and tested for specific conductance. The results, shown in tables 4 and 5, demonstrate that the two solutions are homogeneous.

\section{Analysis of Simulated Rainwater}

After establishing the homogeneity of the solutions by the measurement of conductivity, the statistical design for the sampling and analysis of the other components was configured. Each component was to be determined in triplicate in each of three bottles (selected from the beginning, middle and end of the bottling operation) by each technique. Because of experimental exigencies of some techniques, this analysis design was not strictly adhered to in every case, but was followed whenever possible.

The techniques used in the analysis of SRM 2694 were ion chromatography (IC), conductivity, potentiometry, coulometry, isotope dilution mass spectrometry (IDMS), spectrophotometry, laser enhanced ionization flame spectrometry (LEIS), flame emission spectrometry (FES), inductively coupled plasma (ICP), and 
Table 4. Homogeneity test-specific conductance of SRM 2694-I in units of microsiemens per centimeter at $25^{\circ} \mathrm{C}$.

\begin{tabular}{lll}
\hline \hline Bottle & Run \#1 & Run \#2 \\
\hline No. & 25.43 & 25.52 \\
\hline $101 \mathrm{a}$ & 25.48 & 25.50 \\
$101 \mathrm{~b}$ & 25.45 & 25.44 \\
$102 \mathrm{a}$ & 25.43 & 25.47 \\
$102 \mathrm{~b}$ & 25.48 & 25.50 \\
$103 \mathrm{a}$ & 25.47 & 25.44 \\
$103 \mathrm{~b}$ & & \\
& 25.44 & 25.47 \\
$104 \mathrm{a}$ & 25.46 & 25.50 \\
$104 \mathrm{~b}$ & 25.45 & 25.44 \\
$105 \mathrm{a}$ & 25.45 & 25.47 \\
$105 \mathrm{~b}$ & 25.44 & 25.48 \\
$106 \mathrm{a}$ & 25.50 & 25.48 \\
$106 \mathrm{~b}$ & 25.48 & 25.46 \\
$107 \mathrm{a}$ & 25.44 & 25.50 \\
$107 \mathrm{~b}$ & & \\
& 25.46 & 25.48 \\
$108 \mathrm{a}$ & 25.45 & 25.45 \\
$108 \mathrm{~b}$ & 25.49 & 25.48 \\
$109 \mathrm{a}$ & 25.45 & 25.48 \\
$109 \mathrm{~b}$ & 25.47 & 25.44 \\
$110 \mathrm{a}$ & 25.46 & 25.46 \\
$110 \mathrm{~b}$ & & \\
& & $25.47 \mu \mathrm{S} / \mathrm{cm}$ at \\
& & $25.0{ }^{\circ} \mathrm{C}$ \\
Mean & & 0.02 \\
\hline Std. Dev. of a Single Meas. & \\
\hline
\end{tabular}

Table 5. Homogeneity test-specific conductance of SRM 2694-II in units of microsiemens per centimeter at $25^{\circ} \mathrm{C}$.

\begin{tabular}{|c|c|c|}
\hline $\begin{array}{c}\text { Bottle } \\
\text { No. }\end{array}$ & Run \#1 & Run \#2 \\
\hline $1 a$ & 130.1 & 130.3 \\
\hline $1 b$ & 129.4 & 130.2 \\
\hline $2 a$ & 129.8 & 130.0 \\
\hline $2 b$ & 129.8 & 129.6 \\
\hline $3 a$ & 130.2 & 129.8 \\
\hline $3 b$ & 130.1 & 129.7 \\
\hline $4 a$ & 130.1 & 130.0 \\
\hline $4 b$ & 130.3 & 130.2 \\
\hline $5 a$ & 129.4 & 129.8 \\
\hline $5 b$ & 130.3 & 130.2 \\
\hline $6 a$ & 129.6 & 129.9 \\
\hline $6 b$ & 130.0 & 130.7 \\
\hline $7 a$ & 130.2 & 130.8 \\
\hline $7 \mathrm{~b}$ & 130.4 & 129.9 \\
\hline $8 \mathrm{a}$ & 130.1 & 129.9 \\
\hline $8 b$ & 130.4 & 130.8 \\
\hline $9 \mathrm{a}$ & 129.9 & 129.7 \\
\hline $9 b$ & 130.1 & 130.1 \\
\hline Mean & 130.1 & $\mu \mathrm{S} / \mathrm{cm}$ at $25.0^{\circ} \mathrm{C}$ \\
\hline \multicolumn{2}{|c|}{ Std. Dev. of a Single Meas. } & 0.3 \\
\hline
\end{tabular}

flame atomic absorption spectrometry (FAAS). Details of the analytical procedures for each technique will be presented in a forthcoming publication. An overview of the methods will be given here.

Ion chromatography was used to determine the concentrations of fluoride, chloride, nitrate, sulfate, sodium, potassium, and ammonium. Dual channel, dual column IC with hollow fiber chemical suppressor systems was employed. For each level and each component, three calibration points (peak height versus concentration) which bracketed closely the concentrations of the individual components were established. Chloride, nitrate, and sulfate were determined sequentially under one set of chromatographic conditions. A different set of conditions, involving an extremely weak carbonate eluent, was required to resolve the fluoride peak from the negative water-dip to allow the accurate determination of the fluoride concentrations. The cations were determined using a hydrochloric acid eluent. A concern about the stability of ammonium ion will be discussed below.

The specific conductance was measured using a diptype conductance cell of nominal cell constant $0.1 \mathrm{~cm}^{-1}$ and an $\mathrm{AC}$ conductivity bridge operating at $1 \mathrm{kHz}$. Measurements for certifications were made at $25.0^{\circ} \mathrm{C}$ by thermostating the solutions in a water-jacketed beaker, the outer chamber of which contained circulating constant temperature water to maintain the temperature at $25^{\circ} \mathrm{C}$. The exact cell constant of the cell was determined using 0.001 demal $\mathrm{KCl}$, which has a specific conductance of 146.93 microsiemens per centimeter $[\mu \mathrm{S} / \mathrm{cm}]$. Measurements were also made at temperatures ranging from $20^{\circ} \mathrm{C}$ to $28^{\circ} \mathrm{C}$ to establish the temperature coefficient for the specific conductance of these solutions. The temperature coefficient for both levels was determined to be $1.5 \%$ per ${ }^{\circ} \mathrm{C}$ at $25.0^{\circ} \mathrm{C}$.

Potentiometry was used to measure $\mathrm{pH}$, fluoride, ammonium, and chloride. Measurements of $\mathrm{pH}$ were made with a combination glass electrode according to the procedure established at NBS. All measurements were corrected for residual liquid junction potential bias by normalizing to a dilute solution of sulfuric acid, whose $\mathrm{pH}$ had been determined accurately in a hydrogen cell without liquid junction. This cell is of the type used in the certification of the NBS pH buffers. Fluoride was measured with a fluoride ion-selective electrode after addition of a total ionic strength adjustment buffer. Standards which bracketed the concentrations of the rainwater samples were used to calibrate the measurement system. Ammonium ion was determined using an ammonia electrode. The method involves addition of concentrated base to the sample thereby liberating ammonia which diffuses through the semipermeable membrane of the electrode and is sensed by an internal glass 
$\mathrm{pH}$ electrode. The long-term stability of ammonium ion will be discussed below. Chloride was also determined potentiometrically using a chloride ion selective electrode. However, the concentrations of chloride in the simulated rainwater are well below the linear range of response. Thus they are prone to a large uncertainty. The chloride measurements serve only as an indication of concentration and were not used in the final statistical analysis. This method and its values are presented for information only.

The acidity of SRM 2694-II was determined by coulemetric reduction of hydrogen ion in a weighed sample, from which $\mathrm{CO}_{2}$ had been removed by purging with argon $[3,4]$. Titrations were carried out to the neutrality point, determined potentiometrically.

Thermal ionization isotope dilution mass spectrometry was used to determine the total sulfur in the simulated rainwater. This value was then converted to sulfate concentration. Briefly, the method involves the reduction of sulfate to sulfide, distillation of sulfide and collection in a basic arsenic [III] solution, followed by mass spectrometric identification and quantitation of $\mathrm{AsS}^{+}$isotopes $[7,8]$.

Spectrophotometry was used for the determination of nitrate. The procedure was based on the color reaction produced by interaction of nitrate ion and the organic reagent, brucine. Careful attention to experimental procedures and frequent calibration with nitrate standards were required to obtain satisfactory results by this method.

Laser-enhanced ionization flame spectrometry, a new analytical tool in the Inorganic Analytical Research Division, was utilized for the determination of sodium, potassium, calcium, and magnesium. Wavelength scans near the analysis lines were performed to check for spectral background and interfering lines. Minor corrections were applied to the magnesium determination to correct for sodium interference. Magnesium concentration was also determined by flame atomic absorption spectrometry.

Inductively coupled plasma spectrometry was used to measure the calcium concentration in the samples, and flame emission spectrometry was used to determine sodium and potassium. The recovery of each analyte was checked by the single standard addition method.

In addition, the density of the solutions was determined to be $0.997 \mathrm{~g} / \mathrm{ml}$ at $23^{\circ} \mathrm{C}$, essentially identical to pure water at this temperature.

\section{Results and Statistical Analysis}

The average values from each measurement technique are shown in table 6 . Values in parentheses represent the standard deviation of a single measurement. Values in braces are the number of analyses performed. We have used established techniques to calculate weighted averages for the SRM certificate values. The statistical weighting is based on the observed variablities of the various data sets for each analyte. The procedures for deriving the weighted averages and their uncertainties have been described in a previous article [9]. Table 7 contains the certified values and uncertainties for SRM 2694.

The uncertainties associated with fluoride, nitrate, sodium, potassium, calcium, and magnesium are two standard deviations of the certified values. The uncertainties in the certified values for $\mathrm{pH}$, acidity, and specific conductance are based on scientific judgment and experience, rather than on true statistical evaluations because there were no practical second methods of analysis for these components.

The uncertainties tabulated for sulfate are also based on scientific judgment even though there were two independent methods of analysis. For this analyte, the agreements both within and between the methods of analysis were so close that the statistical evaluations of the uncertainties were not believed to be realistic. The uncertainties for these latter four components [pH, acidity, specific conductance, and sulfate] are believed to be roughly equivalent to two standard deviations of the certified values.

The values for chloride and ammonium are listed for information only. Chloride was not certified because the potentiometric method had insufficient precision and accuracy at these levels to corroborate the ion chromatographic data. Until a second independent technique verifies the IC measurements, chloride will not be certified. Ammonium ion was not certified because of very real concerns about the stability of this ion in these solutions.

\section{Discussion}

The problem with the stability of ammonium was first noticed upon reanalysis of RM 8409 eight months after its preparation. The concentration of ammonium in RM $8409-\mathrm{I}$ had decreased from $0.085 \mathrm{mg} / \mathrm{L}$ to $0.025 \mathrm{mg} / \mathrm{L}$. Reanalysis of other samples of simulated rainwater, which were part of a long-term stability study of $\mathrm{pH}$ and conductivity, indicated that similar decreases in ammonium ion had occurred. The decrease was significant when the initial concentration of ammonium was below $0.2 \mathrm{mg} / \mathrm{L}$ and the $\mathrm{pH}$ was above 4.0 (see table 8). The cause of this decrease is not known at this time, but it is suspected to be biological activity. The loss of ammonium does not appear to have significantly affected any 
Table 6. Summary of data for SRM 2694.

\begin{tabular}{|c|c|c|}
\hline $\begin{array}{l}\text { Component } \\
\text { Technique }\end{array}$ & $\begin{array}{c}2694-\mathrm{I}^{2} \\
\text { Mean (Std. Dev.) }\{\mathrm{n}\}\end{array}$ & $\begin{array}{c}2694-\mathrm{II}^{\mathrm{l}} \\
\text { Mean (Std. Dev.) }\{\mathrm{n}\}\end{array}$ \\
\hline $\begin{array}{l}\text { 1. } \mathbf{p H} \\
\text { A. Potentiometry }\end{array}$ & $4.297(.010)^{1}\{7\}$ & $3.591(0.007)\{8\}$ \\
\hline $\begin{array}{l}\text { 2. Specific Conductance } \\
\left(\mu \mathrm{S} / \mathrm{cm} @ 25^{\circ} \mathrm{C}\right) \\
\text { A. Conductimetry }\end{array}$ & $25.47(.02)\{40\}$ & $130.1(.3)\{36\}$ \\
\hline $\begin{array}{l}\text { 3. Acidity, meg/L } \\
\text { A. Coulometry }\end{array}$ & $0.0501(.0015)\{6\}$ & $0.2835(.0045)\{6\}$ \\
\hline $\begin{array}{l}\text { 4. Fluoride, } \mathrm{mg} / L \\
\text { A. IC } \\
\text { B. Potentiometry }\end{array}$ & $\begin{array}{l}0.055(.001)\{12\} \\
0.0532(.0015)\{8\}\end{array}$ & $\begin{array}{l}0.095(.001)\{11\} \\
0.102(.003)\{8\}\end{array}$ \\
\hline $\begin{array}{l}\text { 5. Chloride, } \mathrm{mg} / \mathrm{L} \\
\text { A. IC } \\
\text { B. Potentiometry }\end{array}$ & $\begin{array}{l}0.242(.007)\{9\} \\
0.29(.05)\{8\}\end{array}$ & $\begin{array}{l}1.003(.032)\{9\} \\
0.87(.19)\{8\}\end{array}$ \\
\hline $\begin{array}{l}\text { 6. Nitrate, } \mathrm{mg} / \mathrm{L} \\
\text { A. IC } \\
\text { B. Spectrophotometry }\end{array}$ & $\begin{array}{l}0.513(.007)\{9\} \\
0.49(.02)\{9\}\end{array}$ & $\begin{array}{l}7.141(.044)\{9\} \\
6.98(.05)\{9\}\end{array}$ \\
\hline $\begin{array}{l}\text { 7. Sulfate, } \mathrm{mg} / \mathbf{L} \\
\text { A. IC } \\
\text { B. IDMS }\end{array}$ & $\begin{array}{l}2.688(.018)\{9\} \\
2.697(.012)\{5\}\end{array}$ & $\begin{array}{l}10.83(.06)\{12\} \\
10.81(.03)\{6\}\end{array}$ \\
\hline $\begin{array}{l}\text { 8. Sodium, } \mathbf{m g} / \mathrm{L} \\
\text { A. IC } \\
\text { B. LEIS } \\
\text { C. FES }\end{array}$ & $\begin{array}{l}0.204(.004)\{12\} \\
0.1974(.0030)\{22\} \\
0.212(.004)\{5\}\end{array}$ & $\begin{array}{l}0.412(.002)\{12\} \\
0.411(.006)\{22\} \\
0.432(.006)\{5\}\end{array}$ \\
\hline $\begin{array}{l}\text { 9. Potassium, } \mathrm{mg} / \mathrm{L} \\
\text { A. IC } \\
\text { B. LEIS } \\
\text { C. FES }\end{array}$ & $\begin{array}{l}0.053(.008)\{8\} \\
0.0478(.0015)\{12\} \\
0.055(.001)\{6\}\end{array}$ & $\begin{array}{l}0.107(.010)\{12\} \\
0.1023(.0031)\{16\} \\
0.111(.001)\{6\}\end{array}$ \\
\hline $\begin{array}{l}\text { 10. Ammonium, } \mathrm{mg} / \mathrm{L} \\
\text { A. IC } \\
\text { B. Potentiometry }\end{array}$ & $0.1031(.0039)\{6\}$ & $\begin{array}{l}1.064(.005)\{12\} \\
1.034(.010)\{7\}\end{array}$ \\
\hline $\begin{array}{l}\text { 11. Calcium, } \mathrm{mg} / \mathrm{L} \\
\text { A. LEIS } \\
\text { B. ICP }\end{array}$ & $\begin{array}{l}0.0126(.0004)\{12\} \\
0.015(.002)\{6\}\end{array}$ & $\begin{array}{l}0.0436(.0005)\{12\} \\
0.054(.003)\{7\}\end{array}$ \\
\hline $\begin{array}{l}\text { 12. Magnesium, } \mathrm{mg} / \mathrm{L} \\
\text { A. LEIS } \\
\text { B. FAAS }\end{array}$ & $\begin{array}{l}0.0231(.0003)\{14\} \\
0.025(.001)\{6\}\end{array}$ & $\begin{array}{l}0.0492(.0005)\{13\} \\
0.052(.006)\{6\}\end{array}$ \\
\hline
\end{tabular}

${ }^{1}$ Values in parentheses represent the standard deviation of a single meavurement. Values in braces are the number of determinations.

other components. There have been isolated incidences of visible fungal growth in a few bottles of RM 8409. In such cases the values for nitrate, $\mathrm{pH}$, acidity, and specific conductance, have changed. A solution to this problem involving the sterilization of the "simulated rainwater" is currently under investigation.

It must be noted that the solutions of SRM 2649 are very dilute, unbuffered solutions, and, as such, are very susceptible to contamination causing gross changes in the certified values. Therefore, the solutions should be used immediately upon opening. No assurance can be made as to the composition or stability of the solutions after being opened and recapped. It has been reported to us that a sample of RM 8409 which had been opened, recapped, and stored in a refrigerator lost virtually all of its nitrate content but gained a significant amount of nitrite.

SRM 2694 should be stored in an area free from acid and/or ammonia vapors. These vapors can permeate the polyethylene bottles and contaminate the samples. A set of samples placed in our laboratory refrigerator, which also contained a polyethylene bottle of concentrated ammonium hydroxide, showed a substantial increase in ammonium ion concentration. Refrigeration of SRM 2694 is not necessary. However, the solutions should not be exposed to extreme heat (i.e., temperatures above 
Table 7. Certified values for SRM 2694.

\begin{tabular}{|c|c|c|}
\hline Component & $2694-I^{\prime}$ & 2694-II ${ }^{1}$ \\
\hline $\mathrm{pH} @ 25^{\circ} \mathrm{C}$ & $4.30 \pm 0.02$ & $3.59 \pm 0.02$ \\
\hline $\begin{array}{l}\text { Specific Conductance } \\
\left(\mu \mathrm{S} / \mathrm{cm} @ 25^{\circ} \mathrm{C}\right)\end{array}$ & $26 \pm 2$ & $130 \pm 2$ \\
\hline Acidity, meq/L & $0.050 \pm 0.002$ & $0.284 \pm 0.005$ \\
\hline Fluoride, $\mathrm{mg} / \mathrm{L}$ & $0.054 \pm 0.002$ & $0.098 \pm 0.007$ \\
\hline Chloride,mg/L & $(0.24)^{2}$ & $(1.0)^{2}$ \\
\hline Nitrate, mg/L & $0.501 \pm 0.026$ & $7.06 \pm 0.15$ \\
\hline Sulfate, $\mathrm{mg} / \mathrm{L}$ & $2.69 \pm 0.03$ & $10.8 \pm 0.1$ \\
\hline Sodium, mg/L & $0.205 \pm 0.009$ & $0.419 \pm 0.015$ \\
\hline Potassium, mg/L & $0.052 \pm 0.007$ & $0.106 \pm 0.008$ \\
\hline Ammonium, $\mathrm{mg} / \mathrm{L}$ & - & $(1.0)^{2}$ \\
\hline Calcium, mg/L & $0.014 \pm 0.003$ & $0.049 \pm 0.011$ \\
\hline Magnesium, mg/L & $0.024 \pm 0.002$ & $0.051 \pm 0.003$ \\
\hline
\end{tabular}

\footnotetext{
'The estimated uncertainties are two standard deviations of the certified values, except in the cases of $\mathrm{pH}$, acidity, conductance, and sulfate which are based on scientific judgment and are roughly equivalent to two standard deviations of the certified value.

${ }^{2}$ The values for chloride and ammonium are not certified, but are listed for information only.
}

$35^{\circ} \mathrm{C}$ ) as this will accelerate transpiration of water vapor from the bottles. The bottles, sealed in aluminized bags to retard transpiration, should remain within the sealed bags until just before use. The search for a better container has been initiated.

If conductance and $\mathrm{pH}$ are to be measured on the same sample, conductance should be measured first. Otherwise, leakage of concentrated $\mathrm{KCl}$ from the $\mathrm{pH}$ reference electrode will affect the conductance reading. The measurement of $\mathrm{pH}$ should be performed according to the guidelines set forth in an attachment to the Certificate of Analysis of SRM 2694 and appended to this report (appendix 1). Adherence to this procedure will minimize the bias caused by residual liquid junction potentials. Acidimetric titrations should be performed on samples that have been purged of dissolved carbon dioxide to prevent drifting endpoints and high results.
The contributions of the following individuals at the National Bureau of Standards are gratefully acknowledged: D. G. Friend, D. E. Swearingen, and F. Smithers for bottle cleaning, bottling and packaging; T. C. Rains, R. W. Burke, M. Knoerdel, R. W. Kelly, G. C. Turk, Mo De-Ming, M. S. Epstein, T. A. Rush, T. A. Butler, Han Kai, and M. V. Smith for the chemical measurements; and T. E. Gills and L. J. Powell for coordinating the technical and support aspects from the Office of Standard Reference Materials.

\section{References}

[1] Koch, W. F.; G. Marinenko and Y. C. Wu, The Development of Reference Materials for Acid Rain Research, Environment International 10, 117-121 (1984).

[2] Koch, W. F, and G. Marinenko, Simulated Precipitation Reference Materials: Measurement of $\mathrm{pH}$ and Acidity, Sampling and Analysis of Rain, ASTM STP 823, S. A. Campbell, ed., American Society for Testing and Materials, 10-17 (1983).

[3] Marinenko, G., and W. F. Koch, A Critical Review of Measurement Practices for the Determination of $\mathrm{pH}$ and Acidity of Atmospheric Precipitation, Environment International 10, 315-319 (1984).

[4] Marinenko, G., and W. F. Koch, Evaluation of Methods Used for the Determination of Acidity in Acid Rain Samples, Natl. Bur. Stand. (U.S.), NBSIR 85-3114, 16 pp. (March 1985).

[5] NBS Standard Reference Materials Catalog 1984-1985, C. H. Hudson, ed., Natl. Bur. Stand. (U.S.), Special Publication 260, p. 2, (February 1984).

[6] Moody, J. R., and E. S. Beary, Purified Reagents for Trace Metal Analysis, Talanta 29, 1003-1010 (1982).

[7] Paulsen, P. J., and W, R. Kelly, Determination of Sulfur by Isotope Dilution Thermal Ionization Mass Spectrometry as AsS ${ }^{+}$Ions, Anal. Chem. 56, 707-713 (1984).

[8] Kelly, W. R, and P. J. Paulsen, Determination of Sulfur in NBS Coals by Isotope Dilution Thermal Ionization Mass Spectrometry, in Methods and Procedures used at the National Bureat of Standards to Certify Sulfur in Coal SRM's for Sulfur Content, Calorific Valtie, Ash Content, T. E. Gills, ed., Natl. Bur. Stand. (U.S.), Special Publication 260-94, pp. 7-13 (December 1984).

[9] Paule, R. C., and J. Mandel, Consensus Values and Weighting Factors, J. Res. Natl. Bur. Stand. 87, 377-385 (1982).

Table 8. Stability of ammonium ion in simulated rainwater.

\begin{tabular}{lcccc}
\hline \hline & & & \multicolumn{2}{c}{ Ammonium Ion, mg/L } \\
\cline { 4 - 5 } Sample & Preparation Date & pH & Initial & Feb. 20, 1985 \\
\hline RM 8409-I & June 1984 & 4.3 & 0.085 & 0.025 \\
RM 8409-1I & June 1984 & 3.6 & 1.07 & 1.07 \\
DSPRM V-1 & Feb. 1983 & 4.5 & 0.14 & 0.09 \\
DSPRM V-2 & Feb. 1983 & 3.5 & 1.11 & 1.08 \\
DSPRM V-3 & Feb. 1983 & 4.0 & 0.42 & 0.42 \\
\hline
\end{tabular}




\section{Appendix}

\section{Guidelines for the Measurement of pH in Acidic Rainwater}

This report presents a recommended procedure for the measurement of $\mathrm{pH}$ in acidic rainwater. The intent of this guideline is to improve the accuracy and precision of the $\mathrm{pH}$ measurement with special emphasis on reducing the effect of the residual liquid junction potential. It consists of three major parts: Calibration Sequence, Control Sequence, and Rainwater Measurement Sequence. The purposes of the Calibration Sequence are to accurately calibrate the $\mathrm{pH}$ measurement system with robust buffer solutions, to accurately set the slope, and to verify that the measurement system is functioning properly. The purpose of the Control Sequence is to quantitatively determine the magnitude of the residual liquid junction potential bias for a particular set of electrodes which must be applied in the rainwater measurement sequence to obtain more reliable and intercomparable results. Each sequence should be executed in stepwise order with strict adherence to detail.

Note: This guideline is applicable only to the measurement of $\mathrm{pH}$ in acidic rainwater and acidic low ionic strength aqueous solutions. It should not be used for any other applications as inaccuracies may ensue.

\section{General Directions}

Record the solution temperature to within $1{ }^{\circ} \mathrm{C}$. Record all $\mathrm{pH}$ values to at least $0.01 \mathrm{pH}$ unit. Make all measurements in a quiescent solution. Fully document all calibration and control standards.

\section{Calibration Sequence}

1) Standardize the $\mathrm{pH}$ electrodes and meter using SRM 185f, Potassium Hydrogen Phthalate [pH(S) 4.006 at $25.0^{\circ} \mathrm{C}, 0.05$ molal], or equivalent. ${ }^{1}$ Refer to ASTM D1293, "Standard Test Methods for $\mathrm{pH}$ of Water" for guidance. Record the value. Rinse the electrodes with distilled water (ASTM Type II or better).

2) With the slope adjustment of the meter set at 100 percent, and the temperature adjustment set at the temperature of the buffer solution, check the Nernstian response of the $\mathrm{pH}$ measurement system with a second buffer, SRM 186Ic/186IIc, Potassium Dihydrogen Phosphate/Disodium Hydrogen Phosphate pH(S) 6.863 at $25^{\circ} \mathrm{C}$ ], or equivalent. ${ }^{1}$ Refer to ASTM D1293 for guidance. If the reading for the second buffer is not within $0.03 \mathrm{pH}$ units of the prescribed value, recheck the calibration of the system. ${ }^{2}$ DO NOT CONTINUE until the conditions for calibration and Nernstian response have been satisfied. If the reading for the second buffer is within $0.03 \mathrm{pH}$ units of the prescribed value, record the value and continue.

\section{Control Sequence}

3) Rinse the electrodes thoroughly with distilled water (ASTM Type II or better). Remove drops of water on the electrode by blotting gently (Do Not Rubl) with a clean lab tissue.

4) Insert the electrodes into a clean beaker $(10-20 \mathrm{~mL}$ capacity) containing a portion $(10-20 \mathrm{~mL})$ of the rainwater control standard (e.g., SRM 2694-I). ${ }^{3}$ Be certain that the reference junction and glass bulb are completely immersed. Do not insert the electrodes directly into the polyethylene bottles.

5) Stir or swirl the solution to ensure homogeneity and contact with the electrodes.

6) Allow the solution to settle to a quiescent state (approx. 30 seconds). Record the $\mathrm{pH}$ after the reading has stabilized. ${ }^{4}$

7) Discard this portion of the control standard. Do not use for subsequent control checks or for other analytical determinations such as specific conductance, anions, cations, and acidity.

8) Repeat steps 3 and 7 with a second rainwater control standard (e.g., SRM 2694-II). ${ }^{3}$

9) Calculate the differences between the true $\mathrm{pH}$ values of the rainwater control standard and the values as determined by the $\mathrm{pH}$ measurement system. ${ }^{5}$ Average the differences and apply this bias correction to subsequent rainwater measurements. (For example, if the $\mathrm{pH}$ measurement system displays the $\mathrm{pH}$ of the control 
$0.13 \mathrm{pH}$ units lower than the true value, add $0.13 \mathrm{pH}$ units to the subsequent $\mathrm{pH}$ measurements of rainwater.)

\section{Rainwater Measurement Sequence}

10) Rinse the electrodes thoroughly with distilled water (ASTM Type II or better). Remove drops of water on the electrode by blotting gently (Do Not Rub!) with a clean lab tissue.

11) Insert the electrodes into a clean beaker containing a portion (10-20 $\mathrm{mL}$ ) of the rainwater sample. Be certain that the reference junction and glass bulb are compietely immersed.

12) Stir or swirl the solution to ensure homogeneity and contact with the electrodes.

13) Allow the solution to settle to a quiescent state (approx. 30 seconds). Record the $\mathrm{pH}$ after the reading has stabilized. ${ }^{4}$

14) Apply the bias correction as determined in step 9 and report this corrected value as the $\mathrm{pH}$ of the rainwater sample.

15) Discard this portion of the rainwater sample. Do not use it in other analytical tests.

16) Repeat steps 10 through 15 for subsequent rainwater samples.

17) Repeat the Control Sequence at regular intervals, based upon quality control guidelines, performance history of the measurement system, frequency of measurements, and required accuracy.

\section{Storage of Electrodes}

18) When not in use, soak the electrodes in a solution which is $0.1 \mathrm{~mol} / \mathrm{L}$ potassium chloride and $1 \times 10^{-4}$ $\mathrm{mol} / \mathrm{L}$ hydrochloric acid. Do not store the electrodes in buffers, concentrated acids, concentrated potassium chloride, basic solutions, or distilled water. Do not allow the electrodes to dry out.

19) Use these electrodes exclusively for rainwater measurements.

\footnotetext{
${ }^{1}$ For the highest accuracy and the most direct traceability to the National Bureau of Standards, it is recommended that freshly prepared solutions of Standard Reference Materials (SRM's) be used.

${ }^{2}$ Possible causes for deviation from Nernstian response include:

i) improper calibration

ii) old or contaminated buffer solutions,

iii) insufficient rinsing of the electrodes between solutions,

iv) plugged reference junction,

v) defective electrodes.

vi) defective meter.

It may be necessary to replace the electrodes with a new pair if the non-Nernstian behavior persists even with accurately and freshly prepared buffer standards.

${ }^{3}$.Standard Reference Materials 2694, Simulated Rainwater, is issued by the National Bureau of Standards, Oftice of Standard Reference Materials.

${ }^{4}$ Some systems may require five minutes or more to stabilize. If drifting persists, record the reading after 10 minutes and annotate the data accordingly. With such severe drift, it would be advisable to acquire a different type of $\mathrm{pH}$ electrodes which do not exhibit this adverse characteristic.

${ }^{5}$ The difference should agree to within $0.05 \mathrm{pH}$ units. If not, repeat the Control Sequence.
} 